\title{
Controlled Release of Tramadol from Mixed Matrix Membranes
}

\author{
L. Donato, G. Barbaro, E. Drioli and C. Algieri
}

\begin{abstract}
National Research Council - Institute for Membrane Technology (ITM-CNR), c/o The University of Calabria, cubo 17C, Via Pietro BUCCI, 87036 Rende CS, Italy
\end{abstract}

\begin{abstract}
In this work mixed matrix membranes (zeolite loaded) were prepared and tested as potential devices for the controlled release of tramadol hydrochloride. Due to the hydrophilic nature of the drug, a hydrophobic polymer (polydimethylsiloxane) was chosen for the membrane preparation. NaX zeolites was added to PDMS matrix as modulating agent with the aim to obtain a linear and adequate delivery of the drug in the time as required by the therapeutic needs of this opioid.

About the different investigated systems, the PDMS membrane containing $17 \mathrm{wt} \%$ of zeolite and $0.2 \mathrm{wt} \%$ of drug seems to be the most promising for application as transdermal device. Different mathematical models (Zero order, First order, Higuchi, Bhaskar, and Korsemeyer-Peppas) were used to interpret the drug release mechanism from the different Mixed matrix membranes. The experimental data showed good fit with three different models: Higuchi, Bhaskar and Korsemeyer-Peppas.
\end{abstract}

Keywords: Tramadol hydrochloride, transdermal drug delivery, polydimethylsiloxane, FAU zeolite, NaX-PDMS membranes.

\section{INTRODUCTION}

Controlled release technology is a science rapidly growing due to the development of different polymers (polyurethanes, polyanhydrides and siloxanes) [1-4] and for the advantages over conventional dosage forms, including improved efficacy and reduced toxicity [5]. Today, transdermal drug delivery is an alternative route for systemic drug release because provides different advantages with respect to the conventional therapeutic treatments [6] as the possibility to avoid the metabolism variations and improve the patients compliance [6-7].

Recently, synthetic zeolites were studied in order to investigate their ability to encapsulate and to release drugs [8]. Zeolites are alumino-silicate materials with crystalline structure and micropore aperture size in the range of molecular dimensions $(3-10 \AA)$. It is possible to change their adsorption properties varying the $\mathrm{Si} / \mathrm{Al}$ ratio during the synthesis [9]. Dermal uptake of the zeolite is negligible for long time on the undamaged skin [10]. These materials for their characteristics are used in the pharmacological field. For example, pharmaceutical zeolite-based compositions containing zinc and erythromycin have been used in the treatment of acne [11]. FAU zeolite acts as a slow release agent for different antihelmintic drugs [12].

Up to date, mixed matrix membranes (zeolite loaded) were studied for gas and liquid mixture

*Address corresponding to this author at the National Research Council Institute for Membrane Technology (ITM-CNR), c/o The University of Calabria, cubo 17C, Via Pietro BUCCI, 87036 Rende CS, Italy; Tel: +39-0984-492030;

Fax: +39-0984-402103; E-mail: c.algieri@itm.cnr.it separations [13-15] but the possibility to use them for a sustained drug release was not yet explored. Polymeric materials do not meet the current demands of membrane technology. Mixed matrix membranes (MMMs), consisting of organic polymer with dispersed inorganic fillers (such as zeolite, carbon molecular sieves, silica and carbon nanotubes), combine the properties of the polymer and of the inorganic materials [16]. As demonstrated deeply in the open literature [16], a limit of MMMs is their application in the gas separation processes where the use of glassy polymer is required as matrix host for the inorganic particles. In fact, MMMs prepared with rubbery polymers do not present defects due to the high mobility of the polymeric chains [13]. When glassy polymers are used, the membranes present defects at the polymer-zeolite interface owing to the high rigidity of the polymeric chains [16].

In this work MMMs loaded with $\mathrm{NaX}$ zeolite (faujasite topology) were prepared and investigated as a new transdermal delivery devices of the model drug tramadol hydrochloride (tramadol). The latter is a synthetic opioid from the aminocyclohexanol group widely used for the treatment of the pain caused by surgical operation and chronic disease [17, 18]. The half-life of the drug is about 5.5 hours and in order to maintain the effective plasma concentration it dosage regimen is 50 to $100 \mathrm{mg}$ every 4 to 6 hours with a maximum dosage of $400 \mathrm{mg} /$ day [19].

In this study, the release of tramadol from the MMMs (zeolite loaded) was explored with the aim to evaluate the effect of zeolite on the release kinetic of 
the drug. Different mathematical models (Zero order, First order, Higuchi, Bhaskar, and KorsemeyerPeppas) were also used to interpret the drug release mechanism from the different MMMs.

\section{MATERIAL AND METHODS}

\section{Materials}

Tramadol $\left(\mathrm{C}_{16} \mathrm{H}_{25} \mathrm{NO}_{2} \cdot \mathrm{HCl}, \geq 99 \%\right)$ having molecular weight of $299.84 \mathrm{Da}$ was purchased from Sigma Aldrich (Figure 1a).

Polydimethylsiloxane (PDMS) (Sylgard (R) 184 silicone elastomer) (Figure 1b) supplied by Dow Corning Co. has a kit containing a base (specific gravity at $25{ }^{\circ} \mathrm{C} 1.05 \mathrm{~g} / \mathrm{cm}^{3}$, viscosity $5000 \mathrm{cSt}$ ) and a curing agent (specific gravity at $25{ }^{\circ} \mathrm{C} 1.03 \mathrm{~g} / \mathrm{cm}^{3}$, viscosity $110 \mathrm{cSt}$ ).

Dichloromethane $\quad\left(\mathrm{CH}_{2} \mathrm{Cl}_{2}, \quad 99.5 \%\right)$ and tetrahydrofuran $\left(\mathrm{C}_{4} \mathrm{H}_{8} \mathrm{O}, 99.9 \%\right)$ were purchased from Carlo Erba Reagenti.

$\mathrm{NaX}$ zeolite (Figure 1c) was purchased by Aldrich (particle size $\sim 2 \mu \mathrm{m}$ and $\mathrm{Si} / \mathrm{Al}=1.2$ ). Before using, zeolite crystals were purified using a series of centrifugation and rinsing steps to remove the amorphous materials. The procedure was repeated until to low the $\mathrm{pH}$ value from 10 to 7 . Finally, the zeolite particles were activated at $500{ }^{\circ} \mathrm{C}$ and stored into a dryer to avoid water adsorption.

\section{HPLC Analysis}

The quantitative determination of the drug was performed on a LaChrom D7000 HPLC system
(Hitachi) equipped with L-7400 UV detector. Analysis were carried out using the column Prevail C18, $5 \mu \mathrm{m}$, $250.4 .6 \mathrm{~mm}$ (Alltech, Italy). The mobile phase was acetonitrile/ $\mathrm{KH}_{2} \mathrm{PO}_{4} 50 \mathrm{mM}$ at $\mathrm{pH}=3(25 / 75 \mathrm{v} / \mathrm{v})$. The operating conditions were: flow rate of $1.05 \mathrm{~mL} \mathrm{~min}^{-1}$, temperature of $25{ }^{\circ} \mathrm{C}$, pressure of 120 bar and wavelength of $220 \mathrm{~nm}$.

\section{Membrane Preparation}

The membranes were prepared by the phase inversion technique using the dry method [19]. It consists in a dissolution of a polymer in a proper solvent and cast the solution on a suitable plate. Subsequently, the solvent is evaporated to obtain a dense homogeneous membrane.

In this paper the PDMS polymer was dissolved in $\mathrm{CH}_{2} \mathrm{Cl}_{2}$ (curing agent and base with a ratio 1:10 on weight basis). Afterwards, the tramadol was added to the polymer solution with the aim to evaluate the release of this drug from the membrane. The membranes PDMS-TRAMA based were obtained pouring the solution on a Teflon plate that in turn was put in an oven for 12 hours at $60{ }^{\circ} \mathrm{C}$ to allow the solvent evaporation and the cross-linking of the polymeric material.

To fabricate MMMs, the zeolite particles were dispersed in the solvent in an ultrasonic bath for 15 min. The polymer and the drug were then added and the resulted dispersion was stirred magnetically at room temperature for 4 hours. In addition, during this period, three sonications of $15 \mathrm{~min}$ each one were done to guarantee a well-dispersed suspension. Subsequently, the dispersion was poured on a Teflon

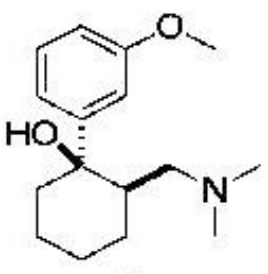

a

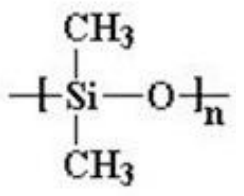

b

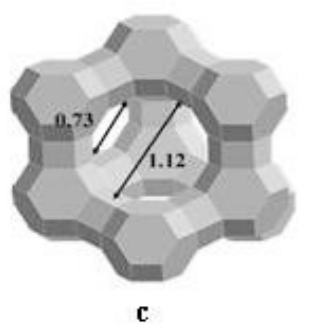

Figure 1: Structure of: (a) tramadol; (b) PDMS; (c) NaX zeolite. 
Table 1: Composition of the Different Prepared Membranes

\begin{tabular}{|c|c|c|c|}
\hline Sample & PDMS (wt\%) & NaX (wt\%) & Tramadol (wt\%) \\
\hline \hline PDMS-TRAMA 0.2\% DL & 99.8 & - & 0.2 \\
\hline PDMS-TRAMA 0.4\% DL & 99.6 & - & 0.4 \\
\hline PDMS-TRAMA 0.6\% DL & 99.4 & 8 & 0.6 \\
\hline PDMS-NaX 8\%-0.2\% DL & 91.8 & 17 & 0.2 \\
\hline PDMS-NaX 17\%-0.2\% DL & 82.8 & 17 & 0.2 \\
\hline PDMS-NaX 17\%-0.4\% DL & 82.6 & 17 & 0.4 \\
\hline PDMS-NaX 17\%-0.6\% DL & 82.4 & 34 & 0.6 \\
\hline PDMS-NaX 34\%-0.2\% DL & 65.8 & & 0.2 \\
\hline
\end{tabular}

plate that was placed in an oven for 12 hours at $60^{\circ} \mathrm{C}$ to allow the cross-linking of the material and the membrane formation.

The composition of the different prepared samples (in terms of drug loading (DL) and zeolite content) was reported in Table 1.

\section{Membrane Characterization}

\section{Morphological Analysis}

Top view and cross-section of the prepared samples were analysed by using a Cambridge Zeiss LEO 400 scanning electron microscope (SEM). Membranes were broken in liquid nitrogen to keep unalterated the film structure.

The thickness of the membranes was measured by using a digital micrometer (Carl Mahr D7300 Esslingen a.N.) averaging 15 measurements. The standard deviation calculated on the sample was about $8 \%$.

\section{Water Contact Angle Measurements}

The wettability of the membranes was evaluated by means of water contact angle (WCA) measurements. Contact angle of water droplets were measured at room temperature with a CAM 200 contact angle meter (KSV Instruments LTD, Helsinki, Finland). The drop was formed depositing water onto the membrane surface with an automatic microsyringe. Both sides of the membrane were tested. At least 30 measurements on different regions of each sample were averaged per each CA value. Standard deviations are indicated as error.

\section{In Vitro Release}

The drug release tests were carried out as reported in the literature [20-22]. The experiments were performed immersing the membranes (area of 28.16 $\mathrm{cm}^{2}$ ) in $0.5 \mathrm{~L}$ of phosphate-buffered solution $(50 \mathrm{mM}$, $\mathrm{pH}$ 7.4) maintained at $37{ }^{\circ} \mathrm{C}$ under continuous stirring (200 rpm). During the experiments $500 \mu \mathrm{l}$ were withdrawn (each twenty minutes during the first hours and then deferred over time). The concentration of the drug present in the medium was estimated by HPLC analysis and the drug release percent was determined using the following equation:

Drug release $(\%)=\left(\frac{M_{t}}{M_{i}}\right) \cdot 100$

Where, $M_{i}$ and $M_{t}$ are the initial amount of drug and the amount of drug released at the time $t$, respectively. All the experiments were repeated three times. Due to a concentration gradient of the drug between the membrane and release medium, the tramadol migrates from the initial position in the membrane to the medium.

\section{Release Profile Analysis}

The release data were fitted with different mathematical models (Zero order, First order, Higuchi, Bhaskar and Korsemeyer-Peppas) to interpret the drug release mechanism from the membranes.

The zero order equation (2) is:

$Q_{t}=Q_{0}+k_{0} t$

Where $Q_{t}$ is the amount of drug dissolved in the time t, $Q_{0}$ is the initial amount of drug in the solution and $k_{0}$ is the zero order release constant [23]. This model represents the drug release from matrix tablet and transdermal devices [24].

The drug release that follows the first-order kinetics is expressed by the equation (3): 


$$
-\log \left(1-\frac{M_{t}}{M_{\infty}}\right)=\frac{k t}{2.303}
$$

Where $M_{t}$ is the amount of the drug release at time $t, M_{\infty}$ is the amount of the drug release after infinite time and $k$ is a release rate constant. This model is used to describe the release of water-soluble drug [23].

The Higuchi model is described by the equation (4):

$\frac{M_{t}}{M_{\infty}}=k_{H} t^{\frac{1}{2}}$

Where $\mathrm{k}_{\mathrm{H}}$ is the Higuchi dissolution constant. This model is based on the following hypotheses: 1) initial drug concentration in the matrix is higher than drug solubility; 2) drug diffusion occurs only in one dimension; 3) drug particles are smaller than system thickness; 4) matrix swelling and dissolution are negligible; 5) drug diffusivity is constant [24]. This model can be used to describe the drug dissolution from several types of modified release pharmaceutical dosage forms, as some transdermal systems and matrix tablets with water soluble drugs [25,26].

The equation (5) describes the Bhaskar model:

$-\log \left(1-\frac{M_{t}}{M_{\infty}}\right)=B t^{0,65}$

$B$ is the kinetic constant. This model is used to describe the drug diffusion through the resins and inorganic materials $[27,28]$.

The Korsemeyer-Peppas model is expressed by the equation (6):

$\log \frac{M_{t}}{M_{\infty}}=\log k+n \log t$

$k$ is a release rate constant that incorporates structural and geometric characteristics of the tablet and $n$ is a diffusional exponent indicative of the release mechanism as reported in Table 2 [29].

Table 2: Interpretation of Diffusional Release Mechanisms from Polymeric Films

\begin{tabular}{|c|c|}
\hline Release exponent (n) & Drug transport mechanism \\
\hline \hline 0.5 & Fickian release \\
\hline 0.5 & Non Fickian release (anomalous) \\
$<1$ & Case II transport \\
\hline 1 & \\
\hline
\end{tabular}

\section{RESULTS AND DISCUSSION}

Top-view and cross-section of the different samples PDMS based are shown in Figures 2a-2e. The top-view of the PDMS membranes loaded only with the tramadol is very smooth (Figure $\mathbf{2 a}$ and $\mathbf{2} \mathbf{b}$ ). Referring to the mixed matrix membranes, all micrographs show the crystals well embedded in the rubbery matrix indicating a good interaction between the two different materials due to the high mobility of the polymeric chains. The cross sections confirm a good crystals distribution for the all membranes (see Figure $\mathbf{2 c - 2 e}$ ).

The thickness of the all prepared membranes, measured using a digital micrometer, ranged from 1.1$1.6 \mathrm{~mm}$.

Contact angle measurements showed that all the prepared membranes exhibited a hydrophobic character even if the addition of the zeolite has determined changes of the contact angle values for both sides of the membranes. In fact, air and Teflon side of the pure PDMS present the same hydrophobic character that remains constant also after the addition of tramadol, as it is shown in Figure $\mathbf{3}$ for the samples containing $0.2 \% \mathrm{DL}$. On the other hand, in the case of MMMs increasing the zeolite content (from 8 wt\% to 17 wt\%) also increases the contact angle value of the side exposed to the air. This because an increase of the zeolite content determines a higher particles sedimentation on the membrane side exposed to the Teflon plate (for the action of the gravitational force as also reported in literature [30]). Consequently, the hydrogen bonds between the different oxydrilic groups of the zeolites are mainly formed both inside and on the Teflon side of the membrane. Therefore, the zeolite particles exposed to the air their hydrophobic portion (Si-O-Si). Hence, the Teflon side of the membrane presents a lower contact angle value.

Figure 4 reports the release profile of tramadol for the PDMS-TRAMA membranes at different drug loading.

As it is shown, the release kinetic was not influenced by DL. Taking into account the high solubility of tramadol in the aqueous medium, the use of a hydrophobic polymer like PDMS ensured a slow release of the drug in the time. However, the release kinetics are not enough linear as required by the therapeutic needs of this opioid [31]. On the basis of these results a modulating agent such as zeolite was added into the polymeric matrix with the aim to promote 

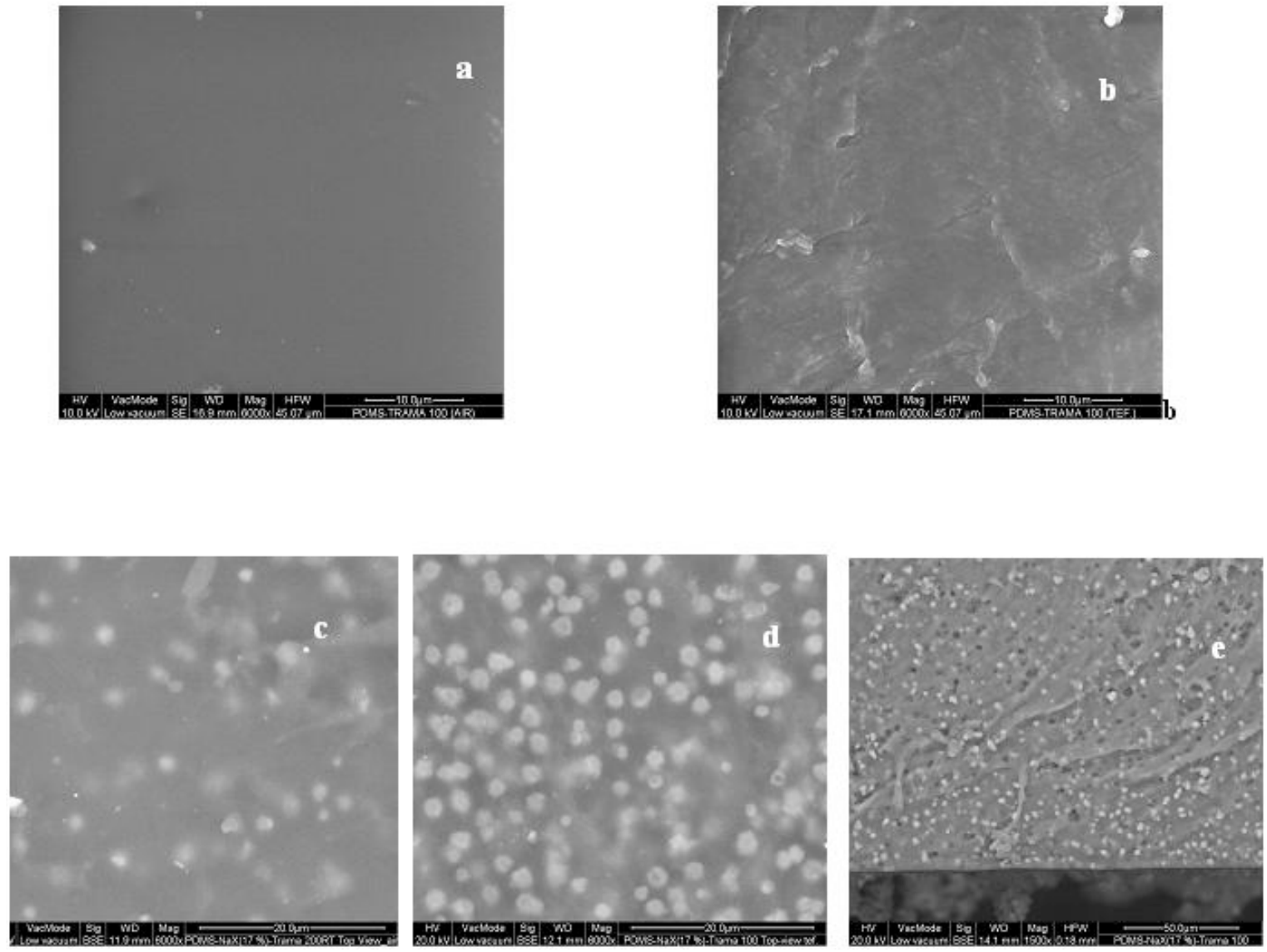

Figure 2: SEM micrographs of different membranes: Top-view of $\mathbf{a}$ ) air side and $\mathbf{b}$ ) Teflon side of PDMS-TRAMA $0.2 \%$ DL. c) air side; d) Teflon side and e) cross-section of PDMS-NaX17\%-0.2 \% DL.

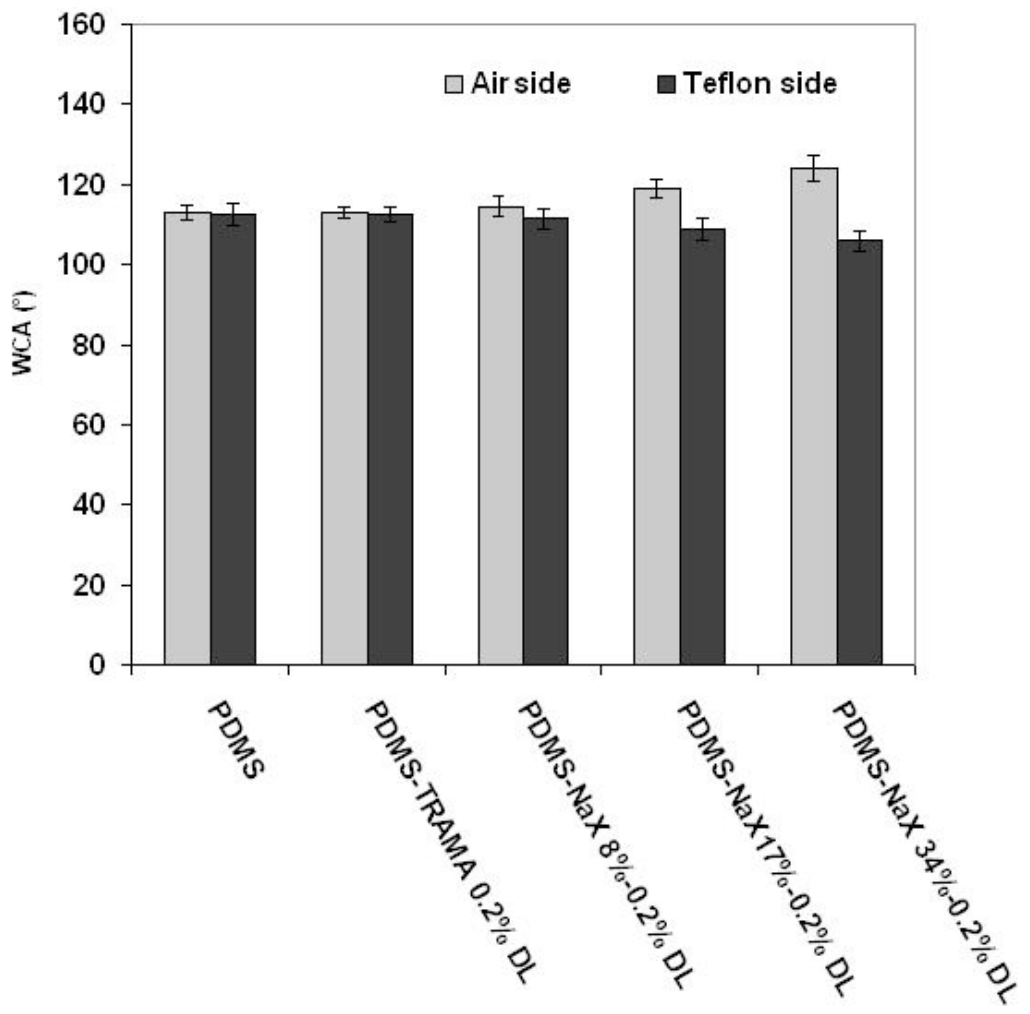

Figure 3: WCA values of the different prepared membranes. 


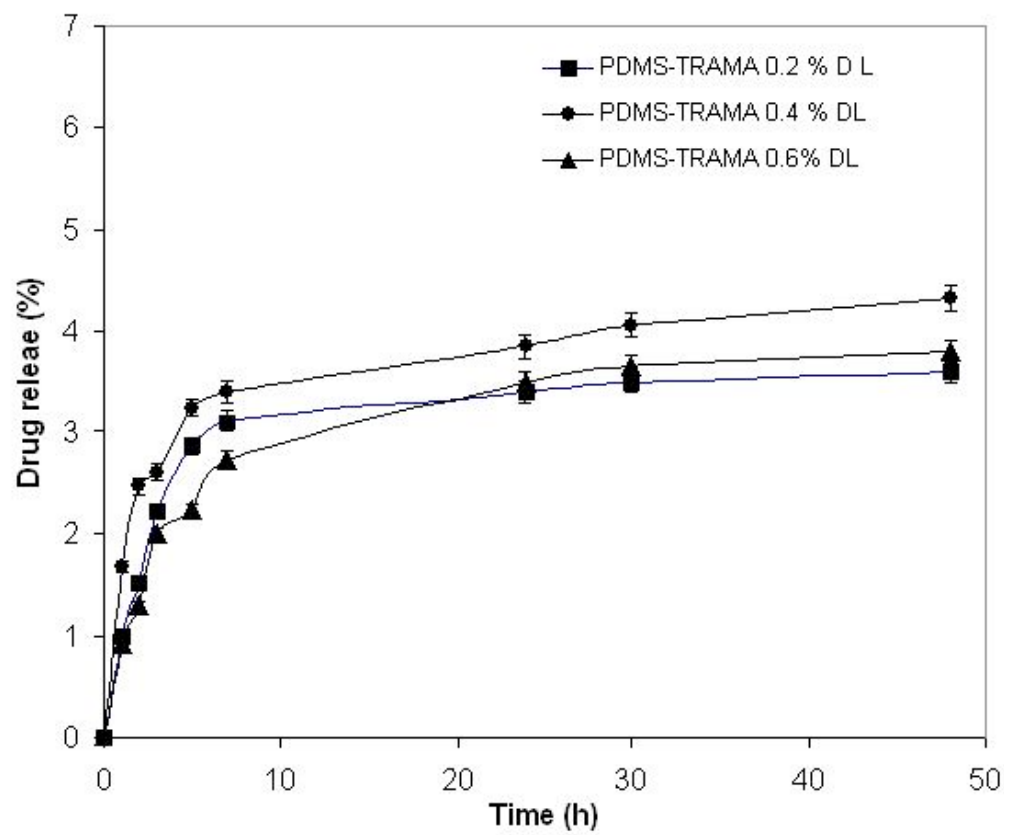

Figure 4: Release profile of tramadol from PDMS-TRAMA membranes at different DL.

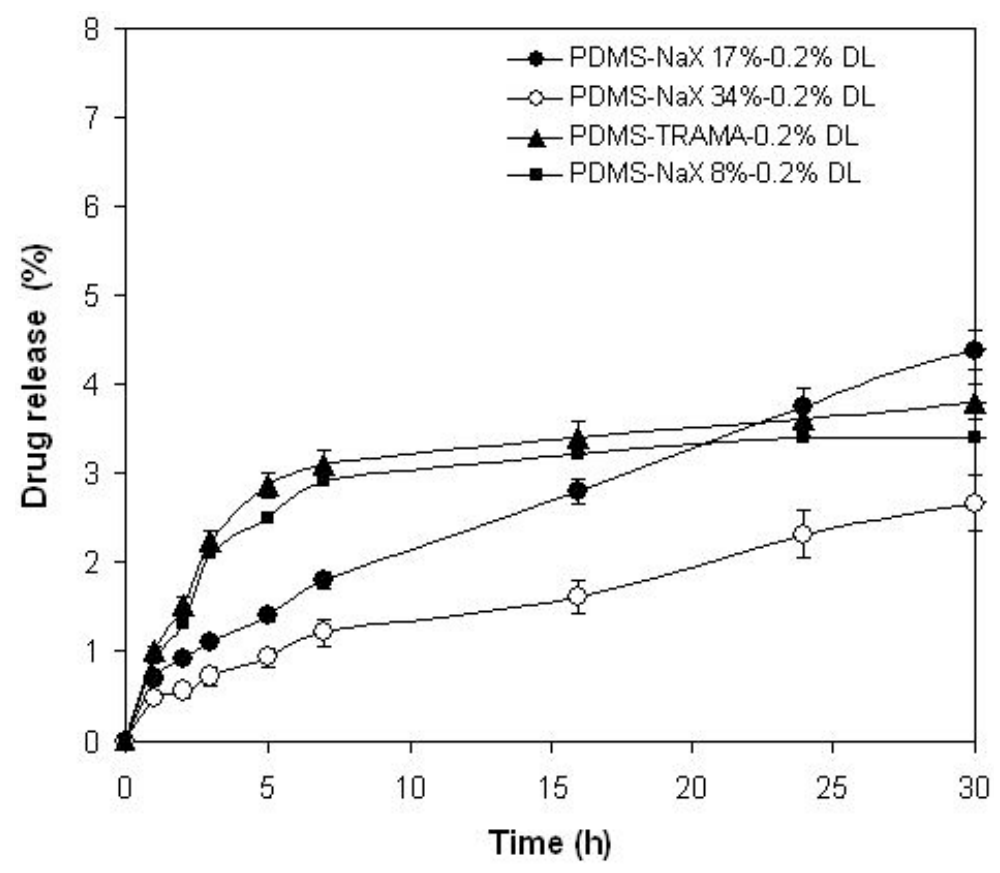

Figure 5: Effect of zeolite content on tramadol release from PDMS-NaX membranes (0.2\% DL).

a more linear and adequate delivery in the time. In this perspective, various MMMs at $0.2 \% \mathrm{DL}$ and low, medium and high zeolite content were prepared and tested. The effect of the zeolite on the release profile of tramadol from the MMMs is shown in Figure $\mathbf{5}$.

As it can be seen, at low $\mathrm{NaX}$ content ( $8 \mathrm{wt} \%$ ) in the polymeric matrix was not observed any significant effect of the zeolite on the release rate. Increasing further the zeolite amount (17 wt\%) a more linear release behaviour was obtained. This results is due to the interaction of the hydrophilic zeolite with the polar molecules of tramadol [32] which leads to a slower delivery to the medium. However, at high zeolite content (34 wt\%) an excessive delay of the release rate was observed. This last result is due to two different aspects. First of all, the formation of zeolite clusters into the polymeric matrix that hinderd the release of the drug. Secondly, the increase of the zeolite content from $17 \mathrm{wt} \%$ to $34 \mathrm{wt} \%$ determined a more tortuous diffusion pathway of the drug into the polymeric matrix. 


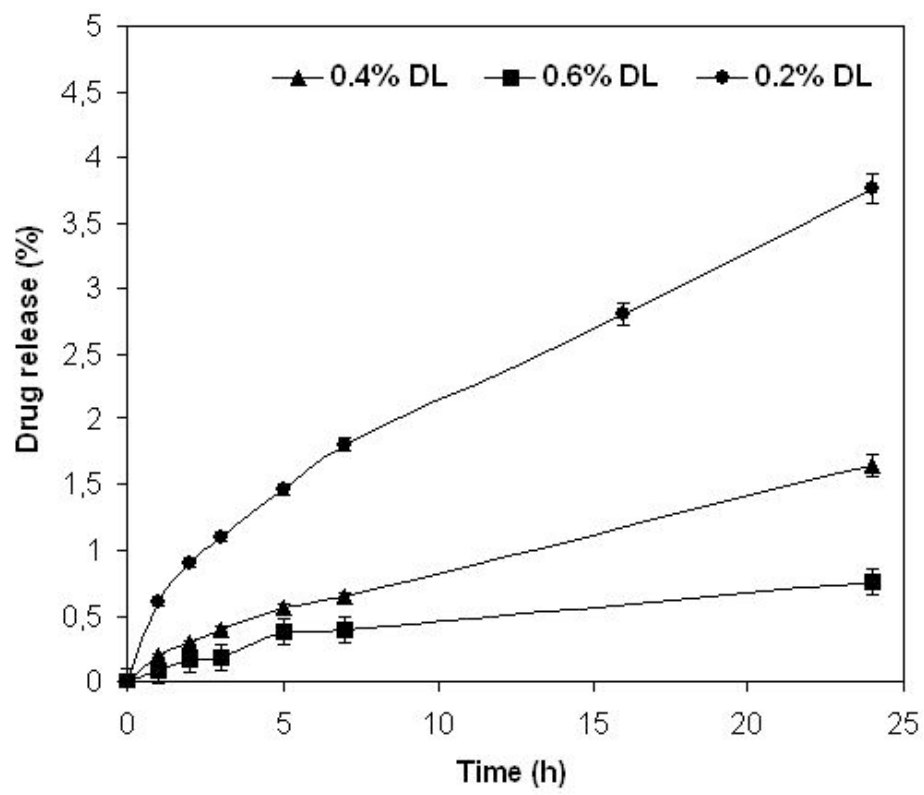

Figure 6: Effect of $\mathrm{DL}$ on tramadol release from mixed matrix membranes ( $\mathrm{NaX} 17 \mathrm{wt} \%)$.

On the basis of these results, other MMMs at 17 wt $\%$ of zeolite content were prepared increasing the DL. Results are shown in Figure 6.

An Increase of DL from $0.2 \%$ to $0.6 \%$ determined a decrease of the drug release rate. This behaviour can be attributed to the precipitation of the drug into the polymer matrix when its amount exceeds the solubility limit in the polymer as also confirmed by literature [33]. About the different investigated systems, the PDMSNaX $17 \%-0.2 \%$ DL membrane seems to be the most promising for application as transdermal device.

Different mathematical models (Zero order, First order, Higuchi, Bhaskar and Korsemeyer-Peppas) were used to interpret the drug release mechanism from the MMMs loaded with $0.2 \% \mathrm{DL}$. The model that best fits the release data was evaluated by correlation coefficient $\left(R^{2}\right)$. The release constant and the $R^{2}$ values are given in Table 3. The experimental data showed good fit with three different mathematical models: Higuchi, Bhaskar and Korsemeyer-Peppas. The latter model (see Table 3) indicated a non-Fickian transport behaviour of the drug from the devices exhibiting a relase exponent in the range $0.5<\mathrm{n}<1$.

\section{CONCLUSIONS}

In this work was demonstrated that mixed matrix membranes NaX-loaded can be used as devices for the transdermal controlled release of tramadol. The obtained results evidenced as the release of a polar drug requires the use of a hydrophobic polymer to avoid a fast release. Besides, the presence of the zeolite particles have permitted to obtain a more linear release kinetic. This results is due to the interaction of the hydrophilic zeolite with the polar molecules of the tramadol. However, a high zeolite content (34 wt\%) into the polymeric matrix has determined an excessive decrease of the release rate. About the different investigated systems, the PDMS membrane containing $17 \mathrm{wt} \%$ of zeolite and $0.2 \% \mathrm{DL}$ seems to be the most promising for application as transdermal device.

Different mathematical models (Zero order, First order, Higuchi, Bhaskar, and Korsemeyer-Peppas) were used to interpret the drug release mechanism from the different MMMs. The experimental data showed good fit with three different models: Higuchi, Bhaskar and Korsemeyer-Peppas.

Table 3:

\begin{tabular}{|c|c|c|c|c|c|c|c|c|c|c|}
\hline & \multicolumn{2}{|c|}{ Zero-order } & \multicolumn{2}{c|}{ First-order } & \multicolumn{2}{c|}{ Bhaskar } & \multicolumn{3}{c|}{ Higuchi } & \multicolumn{2}{c|}{ Korsemeyer-Peppas } \\
\hline & $\mathrm{K}_{0}$ & $\mathrm{R}^{2}$ & $\mathrm{~K}$ & $\mathrm{R}^{2}$ & $\mathrm{~B}$ & $\mathrm{R}^{2}$ & $\mathrm{~K}$ & $\mathrm{R}^{2}$ & $\mathrm{n}$ & $\mathrm{R}^{2}$ \\
\hline \hline PDMS-NaX 8wt\%-0.2 DL & 0.02 & 0.92 & 0.04 & 0.94 & 0.04 & 0.97 & 0.052 & 0.97 & 0.51 & 0.98 \\
\hline PDMS-NaX 17\%-0.2\% DL & 0.002 & 0.88 & 0.02 & 0.95 & 0.02 & 0.99 & 0.07 & 0.99 & 0.55 & 0.99 \\
\hline PDMS-NaX 34\%-0.2\% DL & 0.001 & 0.84 & 0.01 & 0.89 & 0.01 & 0.98 & 0.005 & 0.98 & 0.52 & 0.98 \\
\hline
\end{tabular}




\section{ACKNOWLEDGEMENTS}

The authors Thank Dr. M. Davoli, Department of Earth Science (University of Calabria), for SEM micrographs.

\section{REFERENCES}

[1] Uchegbu IF, Schätzlein AG, Polymers in Drug Delivery. CRC press, Taylor \& Francis Group New York 2006; pp. 377-407.

[2] Lawrence EL, Turner IG. Materials for urinary catheters: a review of their history and development in the U. Med Eng Phys 2005; 27: 443-53.

http://dx.doi.org/10.1016/j.medengphy.2004.12.013

[3] Saito Y, Inamura H. Airway stenting. Surg Today 2005; 35: 267-70.

http://dx.doi.org/10.1007/s00595-004-2942-y

[4] Stamatialis DF, Papenburg BJ, Girones M, Saiful S, Bettahalli SNM, Schmitmeier S, et al. Medical applications of membranes: drug delivery, artificial organs and tissue engineering. J Membr Sci 2008; 308: 1-34.

http://dx.doi.org/10.1016/j.memsci.2007.09.059

[5] Sullad AG, Manjeshwar LS, Aminobhavi TM. Controlled release of theophylline from interpenetrating blend microspheres of poly(vinyl alcohol) and methyl cellulose. J Appl Polym Sci 2010; 116: 1226-35.

[6] Limpongsa E, Umprayn K. Preparation and evaluation of diltiazem hydrochloride diffusion-controlled transdermal delivery system. AAPS PharmSciTech 2008; 9: 464. http://dx.doi.org/10.1208/s12249-008-9062-8

[7] Subedi RK, Oh SY, Chun MK, Choi HK. Recent Advances in transdermal drug delivery. Arch Pharm Res 2010; 33: 33951.

http://dx.doi.org/10.1007/s12272-010-0301-7

[8] Rimoli MG, Rabaioli MR, Melisi D, Curcio A, Mondello S, Mirabelli $R$, et al. Synthetic zeolites as a new tool for drug delivery. J Biomed Mater Res A 2007; 87A: 156-64. http://dx.doi.org/10.1002/jbm.a.31763

[9] Martinez C, Corma A. Inorganic molecular sieves: Preparation, modification and industrial application in catalytic processes. Coord Chem Rev 2011; 255: 1558-80. http://dx.doi.org/10.1016/..ccr.2011.03.014

[10] Fruijtier-Pölloth C. The safety of synthetic zeolites used in detergents. Arch Toxicol 2009; 83: 23-25 http://dx.doi.org/10.1007/s00204-008-0327-5

[11] De Gennaro M, Cerri G. Pharmaceutical zeolite-based compositions containing zinc and erythromycin, to be used in the treatment of acne. Patent: WO 02/100420; 2002.

[12] Dyer A, Morgan S, Welles P, Williams C. The use of zeolites as slow release anthelmintic carriers. J Helminthol 2000; 74: 137-41.

[13] Clarizia G, Algieri C, Drioli E. Filler-polymer combination: a route to modify gas transport properties of a polymeric membrane. Polymer 2004; 45: 5671-81.

http://dx.doi.org/10.1016/j.polymer.2004.06.001

[14] Clarizia G, Algieri C, Regina A, Drioli E. Zeolite-based composite membranes: gas transport and surface properties. Micropor Mesopor Mat 2008; 115: 67-74. http://dx.doi.org/10.1016/j.micromeso.2008.01.048

[15] Chung TS, Jiang LY, Li Y, Kulprathipanja S. Mixed matrix membranes (MMMs) comprising organic polymers with dispersed inorganic fillers for gas separation. Prog Polym Sci 2007; 32: 483-507.

http://dx.doi.org/10.1016/j.progpolymsci.2007.01.008
[16] Aroon MA, Ismail AF, Matsuura T, Montazer-Rahmati MM. Performance studies of mixed matrix membranes for gas separation: A review. Sep Purif Technol 2010; 75: 229-42. http://dx.doi.org/10.1016/i.seppur.2010.08.023

[17] Coluzzi F, Mattia C. Chronic non-cancer pain: Focus on once-daily tramadol formulations. Ther Clin Risk Manage 2007; 3(5): 819-29.

[18] Salsa T, Veiga F, Pina ME. Oral controlled-release dosage forms. I. Cellulose ether polymers in hydrophilic matrices. Drug Dev Ind Pharm 1997; 23: 929-38. http://dx.doi.org/10.3109/03639049709148697

[19] Mulder M. Basic Principles of Membrane Technology, Ed. Kluwer Academic Publishers, London 1991; p. 59.

[20] Scott LJ, Perry CM. Tramadol: a review of its use in perioperative pain. Drugs 2000; 60(1): 139-76. http://dx.doi.org/10.2165/00003495-200060010-00008

[21] Acosta N, Aranaz I, Peniche C, Heras A. Tramadol reelase from a delivery system based on alginate-chitosan microcapsules. Macromol Biosci 2003; 3: 546-51. http://dx.doi.org/10.1002/mabi.200300009

[22] Mishra B, Bakde BV, Singh PN, Kumar P. Development and in-vitro evaluation of oral sustained release formulation of tramadol hydrochloride. Acta Pharma Sci 2006; 48: 153-66.

[23] Breck DW. Zeolite Molecular Sieves. Wiley, New York 1974.

[24] Dash S, Murthy PN, Nath L, Chowdhury P. Kinetic modelling on drug release from controlled drug delivery systems. Acta Pol Pharm-Drug Res 2010; 67: 217-23.

[25] Freitas MN, Marchetti JM. Nimesulide PLA microspheres as a potential sustained release system for the treatment of inflammatory diseases. Int J Pharm 2005; 295: 201-11. http://dx.doi.org/10.1016/j.ijpharm.2005.03.003

[26] Higuchi TJ. Mechanism of sustained medication. Theoretical analysis of rate of release of solid drugs dispersed in solid matrices. Pharm Sci 1963; 84: 1464-77.

[27] Shoaib HM, Tazeen J, Merchant AH, Yousuf IR. Evaluation of drug release kinetics from ibuprofen matrix tablets using HPMC. J Pharm Sci 2006; 19: 119-24.

[28] Bhaskar R, Murthy RSR, Miglani BD, Viswanathan K. Novel method to evaluate diffusion controlled release of drug from resinate. Int J Pharm 1986; 28: 59-66. http://dx.doi.org/10.1016/0378-5173(86)90147-X

[29] Ambrogi V, Fardella G, Grandolini G, Perioli L, Tiralti MC. Intercalation compounds of hydrotalcite-like anionic clays with antiinflammatory agents, II: uptake of diclofenac for a controlled release formulation. AAPS Pharm Sci Tech 2002; $3(3): 1-6$.

http://dx.doi.org/10.1007/BF02830624

[30] Prasanthi NL, Manikiran SS, Rama Rao N. Effect of solubility of the drug on the release kinetics from hydrophilic matrices. Int J Pharm Tech Res 2010; 2: 2506-11.

[31] Vankelecom IFJ, Scheppers E, Heus R, Uytterhoeven JB. Parameters influencing zeolite incorporation in PDMS membranes. J Phys Chem 1994; 98: 12390-96. http: //www.rxlist.com/duragesic-drug.htm. http://dx.doi.org/10.1021/j100098a038

[32] Horcajada $P$, Márquez-Alvarez $C$, Ràmila A, Pérez-Pariente $\mathrm{J}$, Vallet-Regì M. Controlled release of Ibuprofen from dealuminated faujasite. Solid State Sci 2006; 8: 1459-65. http://dx.doi.org/10.1016/j.solidstatesciences.2006.07.016

[33] Ma D, McHugh AJ. The interplay of phase inversion and membrane formation in the drug release characteristics of a membrane-based delivery system. J Membr Sci 2007; 298: 156-68.

http://dx.doi.org/10.1016/j.memsci.2007.04.013 